\title{
An Investigation of Social Loafing and Social Compensation in Computer-Supported Cooperative Work
}

Link to publication record in Manchester Research Explorer

\section{Citation for published version (APA):}

McKinlay, A., Procter, R., \& Dunnet, A. (1999). An Investigation of Social Loafing and Social Compensation in Computer-Supported Cooperative Work. In Proceedings of Group'99, the International Conference on Supporting Group Work (pp. 249-257). Association for Computing Machinery.

\section{Published in:}

Proceedings of Group'99, the International Conference on Supporting Group Work

\section{Citing this paper}

Please note that where the full-text provided on Manchester Research Explorer is the Author Accepted Manuscript or Proof version this may differ from the final Published version. If citing, it is advised that you check and use the publisher's definitive version.

\section{General rights}

Copyright and moral rights for the publications made accessible in the Research Explorer are retained by the authors and/or other copyright owners and it is a condition of accessing publications that users recognise and abide by the legal requirements associated with these rights.

\section{Takedown policy}

If you believe that this document breaches copyright please refer to the University of Manchester's Takedown Procedures [http://man.ac.uk/04Y6Bo] or contact uml.scholarlycommunications@manchester.ac.uk providing relevant details, so we can investigate your claim.

\section{OPEN ACCESS}




\section{An Investigation of Social Loafing and Social Compensation in Computer-Supported Cooperative Work}

\author{
Andy McKinlay \\ Department of Psychology \\ University of Edinburgh \\ 7 George Square \\ Edinburgh, EH8 9JZ, Scotland \\ Email: a.mckinlay@ed.ac.uk
}

\author{
Rob Procter \\ Institute for Communicating and \\ Collaborative Systems \\ University of Edinburgh \\ Kings Buildings \\ Edinburgh, EH9 3JZ, Scotland \\ Email:rnp@dcs.ed.ac.uk
}

\author{
Anne Dunnett \\ Department of Education \\ University of Edinburgh \\ Old Moray House \\ Holyrood Road \\ Edinburgh, EH8 8AQ, Scotland \\ a.dunnett@ed.ac.uk
}

\begin{abstract}
The effects of computer-mediated communication on social loafing in brainstorming tasks and social compensation in decision-making tasks are examined. In the first experiment, subjects performed a brainstorming task in either nominal, face-to-face or computer-mediated brainstorming group conditions. Production blocking, in which brainstorming group members interfere with each other's output, was minimised, but the nominal group still out-performed the other groups. In the second experiment, subjects performed a group decision task in face-to-face and computer mediated communication conditions. Social compensation in the presence of social loafing was seen to occur in the first condition, but not in the second. The paper concludes by discussing some of the consequences of both experiments for the future role of computer-mediated communication in group work.
\end{abstract}

\section{Keywords}

Social loafing, social compensation, computer-supported cooperative work, computer-mediated communication

\section{INTRODUCTION}

A major goal of computer-supported cooperative work (CSCW) is to enable people to work together without the restrictions on place and time imposed by conventional 'face-to-face' group work. In order to achieve this, it is argued that it is not necessary that CSCW tools attempt to duplicate the circumstances of face-to-face working in their entirety. There is a considerable body of evidence that, for example, the use of video makes little difference to group behaviour in many CSCW task scenarios $[15,16]$. Indeed, it is argued that CSCW is best conceptualised as a new medium for group work rather than as a diminished form of working face-to-face $[9,28]$.
Nevertheless, we contend that when people communicate or collaborate by means of CSCW tools, the same general sorts of social phenomena arise as is the case when people interact in normal face-to-face settings. What this means is that factors such as social group influences on the individual, and interactional aspects influenced by social identity, can all arise in the case of CSCW, as well as in face-to-face interaction. It therefore remains important to explore both the kinds -- and magnitudes -of effects that are likely to follow on the displacement of face-to-face work by CSCW.

In order to study group behaviour in face-to-face and computer-mediated conditions, we have conducted a series of laboratory-based studies using brainstorming and decision-making as model group tasks. Brainstorming -- the generation of novel ideas -- is a task in which it has been predicted that output per individual is likely to be greater among groups than among people working in isolation [17]. The suggestion is that when working in groups, people hear one another's ideas and this sparks off fresh lines of thought. This provides the brainstorming group with an advantage over similar collections of individuals, 'nominal' groups whose work output is collated for purposes of comparison with the brainstorming group. The principle of brainstorming is that each group member contributes ideas and that the better ones will be improved upon and combined with the ideas of other group members. The claim is that brainstorming groups produce, per member, more and better ideas than nominal groups. This has, however, proved to be hard to verify in practice.

We focus in this paper on the results of an investigation of two important aspects of group behaviour: 'social loafing' - i.e., the tendency for people to work less hard in groups -- and 'social compensation' - i.e., where some group members work harder to make up for others loafing.

The limitations of laboratory studies as a technique for investigating users' requirements for IT systems are now widely known and acknowledged: user behaviour needs to be contextualised to be properly understood; users' 
needs change as they learn and adapt to new technologies. We argue, however, that though they are not a substitute for 'real world' investigation, laboratory studies nevertheless have a useful role to play in helping to map out the design space and to assess the potential impact of design options.

\section{SOCIAL LOAFING AND SOCIAL COMPENSATION}

One of the limits on group performance in brainstorming tasks is said to derive from the social nature of groups $[1,19]$. In particular, the tendency of people to underexert themselves in group contexts has been suggested as one reason for the lack of success of brainstorming groups. It is often observed that when groups of people work together in conventional circumstances the total group output is less than that which would result from summing the outputs of all group members working in isolation $[11,13]$. There is also evidence that this phenomenon of social loafing occurs in cognitive tasks [27], which may explain why brainstorming groups do not out-perform nominal groups in conceptually creative tasks.

Recently, it has been suggested that computer-mediated brainstorming may be more productive than face-to-face brainstorming. Dennis and Valacich [5] have also suggested that computer-mediated brainstorming groups are more effective than nominal computer-mediated groups. Part of the supposed efficiency of computermediated brainstorming lies in the reduction or elimination of production blocking $[6,7,23]$. This is the difficulty caused by interference among group members in their attempts to contribute. Where contributions are spoken, for example, only one group member can contribute at a time, unless he or she speaks over others' contributions, and this reduces the potential amount of that person's contributions. Related issues such as forgetting an unspoken contribution, negatively reevaluating it in the light of what the current speaker says, or having what the current speaker says interfere with one's own thoughts, amplify the problem.

So, it may be that computer-mediated brainstorming actually benefits from some of the differences between working face-to-face and working in computer-mediated conditions because it reduces production blocking. However, optimism about the future of computermediated brainstorming must be tempered by existing evidence about its relative inability to improve upon nominal group outputs. Gallupe, Bastianutti and Cooper [10] have shown that computer-mediated brainstorming does not, in fact, produce improvement upon the output of computer-using nominal groups. This seems to imply that even computer-mediated brainstorming faces production blocking difficulties, although this could be an artefact of the experimental procedures used. Gallupe et al. reported that when their participants responded to questions specifically aimed to assess presence or absence of production blocking, the results showed that computer-mediated brainstorming was no better than face-to-face brainstorming in solving production blocking difficulties. It may be, then, that a computermediated brainstorming system that has better facilities for avoiding production blocking will enhance brainstorming group output. The purpose of the first experiment reported here was to test this possibility.

Gallupe et al. also suggested that the low output generated by their computer-mediated brainstorming groups might also have been caused by social loafing. If this is the case, then merely reducing production blocking should not be enough to increase computer-mediated brainstorming output. It follows that the output of brainstorming groups may be lower than that of nominal groups, due not to production blocking but, rather, to the presence of social loafing.

Social loafing is not an inevitable phenomenon. There is evidence that it is most likely to occur when people feel that their individual efforts are difficult to discern from those of others [30]. A feature that seems to reduce social loafing is the extent to which the group seems meaningful, coherent and cohesive to its members. In particular, it seems as though under some circumstances group members may work harder to try to socially compensate for actual or perceived lack of effort from other group members $[3,29]$. One of the factors which seems to influence whether social compensation will occur when a group member is seen to be loafing is the extent to which the group is important to the individual. So, where group membership is associated with low cohesiveness or low importance, social compensation to remedy the output drop caused by social loafing may also be low.

When intra-group communication is mediated by computer, people are typically unable to employ the range of communicative acts that are available to them when face-to-face. As a consequence, group members may feel less connection with one another and so group cohesiveness may be lower [21]. If this occurs, then one prediction would be that work groups communicating via computer will be less prone to display social compensation in the presence of social loafing. This has serious implications for CSCW, since it suggests that computer-mediated groups may have sufficient psychological reality for their members to engender social loafing, but insufficient to invoke forms of social compensation which might ameliorate the output drop which social loafing causes. The purpose of the second experiment reported here was to test for evidence that face-to-face groups respond more positively to social loafing than computer-mediated groups.

\section{EXPERIMENT ONE}

The experimental hypothesis of this first experiment was that the number of original ideas generated by a nominal group will be greater than that of either a face-to-face brainstorming group or a computer-mediated brainstorming group.

\section{Method}

A one-way factorial design was employed to compare the number of non-redundant ideas generated by face-to-face and computer-mediated brainstorming groups and by nominal (non-computer-mediated) groups. The between participants factor had three levels, representing the three brainstorming conditions: nominal group, face-to-face 
brainstorming group and computer-mediated brainstorming group. The participants were 54 undergraduate computer science students at Edinburgh University who responded to a request for computerliterate students placed in a class newsgroup. 18 participants were randomly allocated to each of three experimental conditions.

In the nominal and face-to-face group conditions, participants were given writing materials. In the nominal group condition these comprised pens and blank A4 sheets of paper. In the face-to-face brainstorming condition, these materials comprised large felt tip markers and blank A3 sheets of paper which were pinned to a large communal notice board, with a separate sheet for each participant. In the computer-mediated brainstorming condition, participants used a computerbased text conferencing tool, X-talk. Each participant's interface comprised scrollable private text entry area and public text areas. Participants were only able to view messages in the public area of the X-talk interface once the sender had depressed the 'Enter' key. This allowed for private text editing and also preserved a basic turntaking structure in the publicly available text. The X-talk tool ran on three Sun workstations.

The topic for the brainstorming task was the same as that used by Gallupe et al.: the 'Thumbs Problem' in which participants are asked to generate ideas about the practical benefits and difficulties posed by having an extra thumb [10].

\section{Procedure}

The 36 participants who were allocated to either the faceto-face brainstorming condition or the computermediated brainstorming condition were further randomly allocated to groups of three. Thus, six groups performed the brainstorming task in the face-to-face condition and six groups performed the task in the computer-mediated condition.

In the nominal group condition, participants performed the Thumbs Problem task as individuals, seated alone in separate rooms. In the face-to-face brainstorming condition, the participants performed the task in groups of three, standing before a communal notice-board. The computer-mediated brainstorming participants performed the task in groups of three, with each group member being at a separate computer workstation sited at different points in a busy computer laboratory, screened from view by portable room dividers, and communicating with one another solely by means of the X-talk conferencing software. The workstations were sited in a busy computer lab so that the participants would be unable to hear one another typing. Gallupe et al. pointed out that if computer-mediated brainstorming participants hear one another typing, this may affect the extent to which they socially loaf [10].

At the beginning of each session, participants were informed of the basic brainstorming rules they were to follow. It was explained that they would be presented with a simple problem for which they were to think of as many solutions as possible. In the nominal group condition, each participant was seated at a desk within a separate room and told to use the available writing materials to record their ideas. In the face-to-face group condition, participants were shown a notice board to which the A3 sheets of paper were attached. They were asked to stand in front of the notice board and to discuss ideas with other group members. It was explained that they were free, at any time, to write on the publicly observable sheets and participants were warned about the danger of forgetting an idea if it was not written down immediately, even if someone else was talking at the time the idea occurred to the participant. Participants were encouraged to review others' sheets as well as listening to what they said. Large felt-tip pens were provided in order to encourage participants to write using relatively large letters, so that other participants could easily read their contributions.

In the computer-mediated brainstorming condition, participants were given instructions in the use of the Xtalk conferencing tool. It was emphasised that they should monitor the public area of the X-talk interface but the danger of forgetting ideas was stressed and they were reminded that they should type their ideas as soon as they occurred. After a short practice session, they then performed the task using X-talk to communicate with one another. All messages were automatically logged.

In all conditions, a nominal time limit was announced of 10 minutes, in order to give participants some idea of how long they should pursue the task. In fact, participants were allowed to continue the task until the experimenter judged that they had lost interest in generating further ideas. The advantage of this procedure is that it removes potential differences across conditions due to dissimilarity in reporting procedure. It might be argued that writing at a desk is a quicker means of recording ideas than writing at a notice board, for example. To take account of this, participants were allowed to continue the task until they had apparently exhausted their ideas. In fact, there was no difference across conditions in the average time spent by participants on the tasks. 


\begin{tabular}{|l||c|r|}
\hline \multicolumn{1}{|c||}{ Group } & M & \multicolumn{1}{c|}{ SD } \\
\hline \hline Nominal & 35.17 & 3.87 \\
\hline Face-to-face brainstorming & 22.17 & 12.58 \\
\hline $\begin{array}{l}\text { Computer-mediated } \\
\text { brainstorming }\end{array}$ & 21.67 & 8.31 \\
\hline
\end{tabular}

Table 1: Mean numbers of ideas generated by different types of groups.

The procedures were designed to minimize productionblocking in the face-to-face and computer-mediated brainstorming groups. In the face-to-face brainstorming condition, participants were able to write up their ideas at any time, and were instructed to do so even if someone else was talking. In the computer-mediated brainstorming condition, participants were able to type ideas into their private area of the X-talk interface at any time, irrespective of what was happening in the public area of the interface.

Gallupe et al. reported that their computer-mediated brainstorming group performed better than their face-toface brainstorming group [10]. They explained this in part by noting that unlike the face-to-face groups, the computer-mediated brainstorming groups were able to view a sample of others' contributions, rather than merely try to remember them. To this extent, the computer-mediated communication system used in the computer-mediated brainstorming condition acted as a memory aid or repository for group contributions. There was no comparable memory aid in their face-to-face condition. Gallupe et al. concluded that the improvement in output observed in the computer-mediated condition might have been due to this memory-aid effect. In the present study, this issue was addressed by providing participants in the face-to-face condition with the public 'notice board' on which participants' contributions were written. Thus participants in the face-to-face condition could review previous contributions in much the same way as participants in the computer-mediated condition could review contributions by scrolling back the screen.

Once all sessions were complete, the total number of non-redundant ideas produced was calculated using established coding rules [2]. These disallowed generalities and ambiguously phrased ideas if the intent was not immediately determinable. All the ideas were coded by two separate, independent markers and crossreferenced for duplications. The participant scores from the nominal group condition were randomly grouped into threes to allow comparison with scores from the other two conditions.

\section{Results}

The output of participants in each of the three conditions showed that the nominal groups were able to generate more ideas than either of the brainstorming groups. The mean number of ideas generated by the six groups within each of the conditions is presented in Table 1 .

Table 1 shows that, as predicted, the largest number of ideas was generated in the group condition while the two brainstorming conditions generated similarly smaller amounts. With an alpha level of $p<.05$, a one-way ANOVA test showed that these differences were significant, $F(2,17)=4.4, p=.03$. Post-hoc LSD tests on these results show that the differences between the nominal group and both the face-to-face brainstorming group and the computer-mediated brainstorming group were significant, while the difference between the faceto-face brainstorming group and the computer-mediated brainstorming group was not significant.

\section{Discussion}

The finding that there was no difference between the face-to-face brainstorming condition and the computermediated brainstorming condition is in contrast with the findings of Gallupe et al. which demonstrated a productivity gain for participants in their computermediated condition [10]. The explanation posed here is that in the earlier study, the relatively successful computer-mediated condition included a memory aid which was absent in the non-computer-mediated condition. The present study suggests that when a memory aid is provided to face-to-face groups, the brainstorming advantage of computer-mediated communication disappears.

The finding that participants in the nominal group condition produced more ideas than did those in the two brainstorming conditions agrees with the earlier work of Diehl and Stroebe [7]. One suggestion in line with Diehl and Stroebe's original conclusions is that in spite of attempts to reduce production-blocking in the face-toface and computer-mediated brainstorming group conditions, some sort of production blocking loss occurred. In Diehl and Stroebe's terms, productionblocking can be understood as an outcome of waiting on other group-members to finish speaking. The person awaiting the turn to speak might forget the idea, or waste time mentally rehearsing it to prevent forgetting or experience the current speaker's contribution as distraction.

In the present experiment, participants in both brainstorming conditions could write or type their ideas immediately, which should have prevented forgetting and rehearsal. This leaves the possibility of distraction in which the participant attends to other participants' contributions instead of his or her own. However, it is not clear that in the current case distraction of this sort unambiguously represents a form of blocking. Given that the whole idea of brainstorming is that one attends to the output of others for the purposes of creativity stimulation, 
it seems inappropriate to describe this as 'blocking'. It is perhaps better to accept that there is some point beyond which refraining from generating one's own output changes from being a search for creative stimulation into social loafing. The fuzziness of this category distinction is one to which many authors can attest.

\section{EXPERIMENT TWO}

It was noted earlier that on some occasions the adverse effects of social loafing on group productivity can be reduced if some group members produce compensation behaviours. The occurrence of such compensation behaviour may be influenced by the extent to which participants feel the group to be important or cohesive. The conclusion drawn was that groups that rely on computer-mediated communication might experience lower levels of 'group-ness' than face-to-face groups, and that in consequence their members will display less compensation behaviour when faced with social loafing. Accordingly, equivalent amounts of social loafing in computer-mediated groups and face-to-face groups may involve greater detriment to group performance in the computer-mediated case than in the face-to-face case. To examine whether this is so, a second experiment was designed to assess whether, when social loafing is identifiably present in group activity, members of computer-mediated groups demonstrate less compensation behaviour than members of face-to-face groups.

Groups of participants were asked to perform tasks in face-to-face and computer-mediated conditions similar to those found in CSCW settings. Each group, unknown to participants, included an experimenter who had instructions to overtly socially loaf. The extent to which average output of participants was affected by the presence of an overt social loafer was then measured, the hypothesis being that social compensation would improve face-to-face brainstorming results, but not computer-mediated brainstorming results.

\section{Method}

In a mixed design, groups of participants were asked to perform a pair of tasks either in a face-to-face group condition or in a computer-mediated group condition. A social loafer was present in one of the tasks and absent in the other. This formed a within-participants social loafing condition.

The participants were 30 undergraduate students at Edinburgh University who responded to a request for computer-literate participants placed in a class news group. Half of the participants were randomly allocated to the face-to-face condition and half to the computer- mediated condition. The fifteen participants within each condition were then further randomly allocated to groups of three participants.

In the face-to-face group condition, participants were given writing materials. Their conversations were recorded using a small portable tape-recorder. In the computer-mediated group condition, participants used Xtalk, the same text-based conferencing tool that was used in the first experiment. In both conditions, the participants' task was to discuss the relative merit of items of survival equipment. Two brief descriptions of accident scenarios were prepared, one located in the Saharan desert and one in the Arctic desert. Each scenario described an aeroplane accident leading to people being stranded in one or other of the two desert regions. The scenario description was accompanied by a list of ten survival equipment items such as knife, frying pan and water purifier, etc.

\section{Procedure}

After 15 participants had been randomly allocated to the face-to-face condition and 15 to the computer-mediated condition, and those two groups had been further randomly sub-divided into groups of three, an experimental assistant joined each of the groups. The fact that the fourth group member was an experimental assistant was not disclosed to the three other experimental participants. The experimental assistant was not known to any of the participants.

The activity of the experimental assistant determined the level of the within-participants social loafing condition. In the overt loafer present condition, the experimental assistant was instructed to withhold effort. The assistant was asked to make no contribution to the task and to make brief, non-responsive replies to direct questions from other group members. In the overt loafer absent condition, the experimental assistant was not instructed to withhold effort and contributed as a normal member of the group.

To check for order effects across the levels of the withinparticipants social loafer condition, counterbalancing was used. Half of the participants performed the Saharan desert survival scenario task first and, of these, half performed the task with a social loafer present and half with a social loafer absent. The other participants performed the arctic desert survival scenario task first and again half performed the task with a social loafer present and half with a social loafer absent. Participants performed the first task and were then allowed a short rest break before performing the second 


\begin{tabular}{|c||c|c||c|c|}
\cline { 2 - 5 } \multicolumn{1}{c||}{} & \multicolumn{3}{c|}{ Type of communication } \\
\cline { 2 - 5 } \multicolumn{1}{c||}{} & \multicolumn{2}{c|}{ Face-to-face } & \multicolumn{2}{c|}{$\begin{array}{c}\text { Computer- } \\
\text { mediated }\end{array}$} \\
\hline $\begin{array}{r}\text { Loafer } \\
\text { status }\end{array}$ & M & SD & M & SD \\
\hline \hline Present & 392.1 & 109.5 & 153.8 & 56.4 \\
\hline Absent & 335.9 & 123.1 & 169.7 & 62.2 \\
\hline
\end{tabular}

Table 2: Mean number of words produced in faceto-face and computer-mediated conditions with social loafer present or absent.

task. In the computer-mediated group condition, task performance was preceded by a short period during which participants were able to familiarize themselves with the X-talk interface.

At the beginning of each session, participants were informed of the nature of the task that they were to perform. It was explained that they were to imagine themselves to be members of a group which had survived the accident described in the accident scenario and that they had to discuss the relative merits of the ten survival items presented in the list which accompanied the scenario description in order to choose the three most valuable items. They were given ten minutes to complete this task.

The aim of the first experiment was to determine whether social loafing occurs in a computer-mediated communication environment. This was measured by number of ideas generated.

In the second experiment, the presence of loafing was guaranteed by the experimental design, and the aim was to establish whether participants tried to compensate for this. In this latter case, a count of number of ideas generated might have under-represented any compensation that took place. Compensation might take a variety of forms. In addition to striving harder to generate more ideas, participants in the condition where the social loafer was present might also work harder to encourage others to do the same. They may also have expended more effort demonstrating to one another that they were working on the problem, as opposed to loafing. It follows that in this case, it was important to measure the total amount of work done, both in terms of idea generation and in terms of other compensatory social strategies such as encouragement to others. Accordingly, in the second experiment, participant effort was measured as total number of words spoken or typed, rather than merely number of ideas generated.

In the face-to-face condition, participants sat around a table and the discussion was audio-recorded. In the computer-mediated group condition, participants sat at Sun workstations, which were located in separate rooms. After the short period to allow participants to become familiar with the X-talk interface, the participants carried out the discussion via X-talk. All messages were automatically logged.
At the end of the experiment, the total number of words produced by each of the three participants within a group was counted. The average of these totals was then computed to provide a measure of overall group output. Participants were also interviewed to ascertain their impressions of their fellow group members' individual levels of effort.

\section{Results}

The average numbers of words per group member generated in the face-to-face group condition and the computer-mediated group condition, when a social loafer was either present or absent, are presented in Table 2.

It was anticipated that participants in the face-to-face condition would, on average, generate more words than those in the computer-mediated condition, since speaking is quicker than typing, and this effect was observed. There was also a interaction effect. When a social loafer was present, average output per participant was higher in the face-to-face condition but lower in the computermediated condition. This interaction was seen to be significant, with alpha set at $p<.01, F(1,28)=6.89, p=$ .014. This appears to support the suggestion that if a group contains a social loafer then compensation, as measured by the average output per group member, will occur in face-to-face groups but will not appear in computer-mediated groups.

\section{Discussion}

The results support the view that when social loafing occurs, its detrimental effect on average output per group member may be reduced by factors such as social compensation. However, this is more likely to occur in face-to-face circumstances than in computer-mediated circumstances. There are at least two possible explanations for this. The reduced influence of social factors like social compensation within computermediated contexts may be the result of lower levels in perceived importance of group membership or group cohesiveness. It may be that, because participants interact with one another only via computer-mediated communication, their sense of belonging to a group of people whose joint interests they share is diminished. Alternatively, reduction in the influence of social factors may be due to participants' inability to perceive loafing in the computer-mediated group condition.

Several studies $[8,12]$ have suggested that working under 
computer-mediated conditions reduces the extent to which co-workers can informally feedback or 'peripherally attend' to what their fellow workers are doing. In the present study, it may be that participants in the computer-mediated condition were, in some way, prevented from noticing the non-input of the experimental assistant in the social loafer present condition.

An examination of transcripts from the computermediated group and face-to-face group conditions suggested that, in the former, participants acted individually or at best in pairs. This finding is consistent with other studies [14]. In contrast, participants in the face-to-face group condition made greater efforts to overcome the objections of others or to justify their own views to the rest of their group. This may be an explanation of the relatively low output in the computermediated group, overt loafer present condition. Participants in the computer-mediated group condition worked on an individualistic basis that may have reflected reduced group cohesion and reduced peripheral attention. The effect of this would have been to prevent participants in the computer-mediated condition from noticing the social loafer's inactivity and, thereby, to inhibit social compensation.

\section{CONCLUSIONS}

Overall, the experiments suggest that for some tasks, output from computer-mediated groups may be lower than that either from collections of individuals or from face-to-face groups.

The first experiment demonstrated reduced output in computer-mediated groups even when production blocking is removed. Following Gallupe at al., this suggests that social loafing occurs in computer-mediated groups [10]. The second experiment demonstrated reduced output in computer-mediated groups in the presence of overt loafing, suggesting that loafinggenerated social compensation does not occur in such groups.

Taken together, the experiments show that computermediated group performance was worse than that of a comparable collection of individuals and also of a comparable face-to-face group. The results would seem to confirm the initial premise that in some circumstances computer-mediated groups may experience the worst of both worlds: computer-mediated groups have sufficient psychological reality to engender social loafing, but insufficient to invoke the social compensation that might otherwise ameliorate the loss in productivity.

The results of these two studies may have important implications for CSCW. They demonstrate that a 'virtual' group is virtual in more ways than one. Not only are its members physically dispersed, but the effects on those members of belonging to the group are diminished.

The computer-mediated groups in this study had to work together using only the most meager of interaction resources. This raises the question of whether better interaction resources would lead to improved results and, specifically, whether the use of technologies such as videoconferencing may help to improve group performance by enhancing group cohesiveness. Though studies suggest that the addition of video has little effect on interactional behaviour -- e.g., speech patterns -- in physically dispersed groups $[15,18]$, it may yet prove significant for improving group perceptions of membership salience or cohesiveness.

The literature on differences between face-to-face and computer-mediated groups provides somewhat conflicting answers to this question. It has been argued that richer interaction media improves group performance $[4,22]$, however, experimental studies suggest that though performance enhancing effects of video have been observed in short-term, or time-limited groups, they are absent in longer-term, or time-unlimited groups [26]. In fact, the issue may not be that computer-mediated groups are unable to generate productivity-enhancing levels of cohesiveness, but that they achieve these levels of cohesion more slowly: yet other studies suggest that computer-mediated groups take longer to develop norms and social relationships [24].

We argue that it is factors such as group cohesion development that may prove increasingly important if the observed trend for CSCW to displace face-to-face group work continues [20]. For example, it is now commonplace for groups to work together even though they may seldom (or even never) meet face-to-face. For such groups, the key issue may not be the impact of CSCW on interactional aspects of behaviour, but on facilitating the development and subsequent maintenance of group identity. A more immediate sense of belonging and cohesiveness through enhanced social presence may explain why, even in circumstances where there is no observable beneficial effect on group performance, CSCW tool users nevertheless consistently report a preference for being linked by video $[16,25]$.

\section{REFERENCES}

1. Abric, J. Experimental study of group creativity: Task representation, group structure and performance. European Journal of Social Psychology, 2, 311-326, 1971.

2. Bouchard, T. and Hare, M. Size, performance and potential in brainstorming groups. Journal of Applied Psychology, 54, 51-55, 1970.

3. Chapman, J., Arenson, S., Carrigan, M. and Gryckiewicz, J. Motivational loss in small task groups: Free riding on a cognitive task. Genetic, Social and General Psychology Monographs, 119(1), 57-73, 1993.

4. Daft, R.L. and Lengel, R.H. Organisational information requirements, media richness and structural design. Management Science, 32, 554-571.

5. Dennis, A. and Valacich, J. Computer brainstorms: More heads are better than one. Journal of Applied Psychology, 78, 531-537, 1993.

6. Diehl, M. and Stroebe, W. Productivity loss in brainstorming groups: Towards the solution of a riddle. Journal of Personality and Social Psychology, 53, 497-509, 1987. 
7. Diehl, M. and Stroebe, W. Productivity loss in idea generating groups: Tracking down the blocking effect. Journal of Personality and Social Psychology, 61, 392-403, 1991.

8. Dix, A. Computer supported cooperative work: A framework. In Rosenberg and Hutchison (Eds.) Design issues in CSCW. Springer Verlag, London, 1994.

9. Galegher, J. and Kraut, R. Computer-mediated communication and collaborative writing: Media influence and adaptation to communication constraints. In Proceedings of the ComputerSupported Cooperative Work (CSCW) Conference, 155-162, 1992.

10.Gallupe, R., Bastianutti, L. and Cooper, W. Unblocking brainstorms. Journal of Applied Psychology, 76(1), 137-142, 1991.

11.Geen, R. Social motivation. Annual Review of Psychology, 42, 377-399, 1991.

12. Gilbert, G. CSCW for real: Reflections on experience. In Diaper and Sanger (Eds.) CSCW in practice: An introduction and case studies. Springer Verlag, London, 1993.

13.Harkins, S. and Szymanski, K. Social loafing and social facilitation: New wine in old bottles. In Hendrick (Ed.) Review of Personality and Social Psychology: Group Processes and Intergroup Relations, vol. 9, 167-188, 1987.

14. Hiltz, S., Johnson, K. and Turoff, M. Experiments in group decision making: Communication process and outcome in face-to-face versus computerized conferences. Human Communication Research, 13(2), 225-252, 1986.

15. Masoodian, M., Apperley, M. and Frederickson, L. Video support for shared workspace interaction: an empirical study. Interacting with Computers, 7(3), 237-253, 1995.

16. Olson, J., Olson, G. and Meader, D. What mix of video and audio is useful for small groups doing remote real-time design work. In Proceedings of the ACM Conference on Human Factors in Computing Systems (Denver Co, May 1995), 362-368.

17. Osborn, A. Applied Imagination, (Rev. Ed.). Scribner, New York, 1957.

18. Oviatt, S. and Cohen, P. The effects of interaction on spoken discourse. In Proceedings of 27th Annual Meeting of the Association of Computational Linguistics, 126-134, 1989.
19.Paulus, P. and Dzindolet, M. Social influence processes in group brainstorming. Journal of Personality and Social Psychology, 64, 575-586, 1993.

20. Rodden, T. Technological support for cooperation. In D. Diaper and C. Sanger (Eds.) CSCW in Practice: An introduction and case studies. Springer Verlag, London, 1993.

21.Spears, R., Lea, M. and Lee, S. De-individuation and group polarisation in computer-mediated communication. British Journal of Social Psychology, 29(2), 121-134, 1990.

22. Short, J., Williams, E. and Christie, B. The social psychology of telecommunications. Wiley, London, 1976.

23. Stroebe, W. and Diehl, M. Why groups are less effective than their members: On productivity losses in idea-generating groups. European Review of Social Psychology, 5, 271-303, 1994.

24.Sudweeks, F. and Allbritton, M. Working together apart: Communication and Collaboration in a Networked Group. In Proceedings of the $7^{\text {th }}$ Australasian Conference of Information Systems (ACIS96), vol 2, 701-12, 1996.

25.Tang, J. and Isaacs, E. Why do users like video? Studies of multi-media supported collaboration. Computer-Supported Cooperative Work, 1, 163-196, 1993.

26. Walther, J.B. Computer-mediated communication: Impersonal, interpersonal and hyperpersonal interaction. Communication Research, 23, 1-43, 1996.

27. Weldon, E. and Gargano, G. Cognitive loafing: the effects of accountability and shared responsibility on cognitive effort. Personality and Social Psychology Bulletin, 14, 159--171, 1988.

28. Whittaker, S. Rethinking video as a technology for interpersonal communications: Theory and design implications. International Journal of HumanComputer Studies, 42, 501-529, 1995.

29. Williams, K.D. and Karau, S. J. Social loafing and social compensation: The effects of expectations of co-worker performance. Journal of Personality and Social Psychology, 61, 570-581, 1991.

30.Williams, K.D., Harkins, S. and Latane, B. Identifiability as a deterrent to social loafing: Two cheering experiments. Journal of Personality and Social Psychology, 40, 303-311, 1981. 